\title{
Safety of Kidney Biopsy when Performed as an Outpatient Procedure
}

\author{
Marco Bonani ${ }^{\mathrm{a}}$ Harald Seeger ${ }^{\mathrm{a}}$ Nina Weber ${ }^{\mathrm{a}}$ Johan M. Lorenzen ${ }^{\mathrm{a}}$ \\ Rudolf P. Wüthrich ${ }^{a}$ Andreas D. Kistler ${ }^{b}$ \\ aDivision of Nephrology, University Hospital Zurich, Zurich, Switzerland; 'bivision of Nephrology, Department of \\ Medicine, Cantonal Hospital Frauenfeld, Frauenfeld, Switzerland
}

\section{Keywords}

Kidney biopsy · Transplant biopsy · Bleeding · Major bleeding $\cdot$ Complications

\begin{abstract}
Introduction: Kidney biopsy remains the gold standard for the diagnosis of most renal diseases. A major obstacle to performing a biopsy is safety concerns. However, many safety measures are not evidence based and therefore vary widely between centers. We sought to determine the rate and timing of kidney biopsy complications in our center, to compare the complication rate between native and transplant kidney biopsies, to evaluate the feasibility of performing kidney biopsies as an outpatient procedure and the value of a postbiopsy ultrasound before discharge, and to identify risk factors for complications. Methods: We performed a single-center, retrospective, observational study at the Division of $\mathrm{Ne}$ phrology of the University Hospital Zurich including all patients who underwent renal biopsy between January 2005 and December 2017. Major bleeding (primary outcome) and any other bleeding or nonbleeding complications (secondary outcomes) were compared between native and trans-
\end{abstract}

karger@karger.com www.karger.com/kbr

Karger $\stackrel{\text { ' }}{5}$
(C) 2021 The Author(s)

Published by S. Karger AG, Basel

This is an Open Access article licensed under the Creative Common Attribution-NonCommercial-4.0 International License (CC BY-NC) (http://www.karger.com/Services/OpenAccessLicense), applicable to the online version of the article only. Usage and distribution for commercial purposes requires written permission. plant kidney biopsies and between inpatient and outpatient procedures and correlated with clinical factors possibly affecting bleeding risk. Results: Overall, 2,239 biopsies were performed in 1,468 patients, 732 as inpatient and 1,507 as outpatient procedures. Major bleeding was observed in 28 (3.8\%) inpatient and in $15(1.0 \%)$ outpatient procedures, totaling to 43 (1.9\%) of all biopsies. Major bleeding requiring intervention amounted to $1.0 \%$ ( $0.5 \%$ of outpatient procedures). Rate of major bleeding was similar between native and transplant kidneys. 13/15 (87\%) bleeding episodes in planned outpatient procedures were detected during the 4-h surveillance period. Risk factors for bleeding were aspirin use, low eGFR, anemia, cirrhosis, and amyloidosis. Routine postbiopsy ultrasound did not change management. Conclusions: Kidney biopsy is an overall safe procedure and can be performed as an outpatient procedure in most patients with an observation period as short as $4 \mathrm{~h}$. The value of routine postbiopsy ultrasound is questionable.

(c) 2021 The Author(s).

Published by S. Karger AG, Basel

Marco Bonani and Harald Seeger contributed equally.
Correspondence to:

Andreas D. Kistler, andreas.kistler@ stgag.ch 


\section{Introduction}

The prevalence of chronic kidney disease (CKD) continues to increase worldwide and represents a major public health issue $[1,2]$. Only few treatments targeting general mechanisms of CKD progression have been proven to retard renal functional decline. However, an increasing understanding of the pathophysiology of certain forms of renal disease has increased our armamentarium for the specific treatment of some forms of CKD [3-7]. Hence, establishing a precise diagnosis is of great importance for disease-modifying treatments of renal diseases. Despite advances in noninvasive diagnostic methods, histological analysis remains the gold standard or even the only reliable diagnostic method for most renal parenchymal diseases. Likewise, identification of the cause for kidney transplant dysfunction often requires tissue analysis. Therefore, kidney biopsy of native and transplant kidneys remains an indispensable diagnostic tool for nephrologists.

Besides cost, a major obstacle to performing a kidney biopsy is safety concerns, and there is interest in a precise estimate of the incidence of complications and the identification of risk factors to allow for an informed decisionmaking on the indication of a renal biopsy. Furthermore, many safety measures are not evidence based. Consequently, biopsy practices and standards vary widely between centers, for example, with respect to postprocedure monitoring, including the routine acquisition of a postbiopsy ultrasound and whether uncomplicated kidney biopsies are performed as outpatient procedures or not. Routine implementation of outpatient kidney biopsy would considerably reduce overall cost of the procedure.

We sought to determine the complication rate of native and transplant kidney biopsies in our center, where approximately 170 kidney biopsies are carried out annually by nephrologists. We routinely perform kidney biopsies as an outpatient procedure unless patients are hospitalized for other reasons. Thus, we specifically aimed to determine the safety of outpatient kidney biopsies, to compare the complication rate between native and transplant kidney biopsies, to evaluate the value of a routine postbiopsy ultrasound evaluation before hospital discharge, and to identify potential risk factors for complications.

\section{Methods}

Study Design, Study Population, and Data Sources

Since January 2005, all patients who underwent a percutaneous renal biopsy procedure at our center (inpatients and outpatients) have been prospectively entered into an internal quality control da- tabase. The retrospective observational study reported here includes all renal biopsies performed at the Division of Nephrology between January 2005 and December 2017 and is based on a review of these prospectively collected data and additional data extraction from our electronic health record (EHR) system. The study was approved by the Cantonal Ethics Committee of Zurich. Patients were exempt from giving written informed consent for this study because of unjustified efforts and since a large proportion of patients could not be contacted for consenting due to loss to follow-up, which would have caused potential bias. However, the majority of patients have given general consent to data use for research, and data extraction from the EHR was limited to these patients. The parameters contained in the internal database as well as the EHR search parameters and the search criteria are listed in online suppl. Table (for all online suppl. material, see www.karger.com/doi/10.1159/000515439). Since several features of the EHR system were newly implemented during the study period, some parameters were available only for a subset of patients. All procedures with either a complication listed in the internal quality control database or with any value that might point to a complication in the EHR search (e.g., a drop in hemoglobin of $>20 \mathrm{~g} / \mathrm{L}$ within 1 week of the biopsy, a CT performed on the day of the biopsy, and an unplanned hospital admission) were reviewed manually by assessing the patient's medical records.

\section{Biopsy Procedure}

All biopsy procedures were performed by 2 physicians under real-time ultrasound imaging, mostly by a renal fellow performing the puncture ("operator") with a supervising staff nephrologist (attending physician/faculty member) holding the ultrasound probe ("sonographer"). As safety thresholds for the biopsy, blood pressure $<160 / 110 \mathrm{~mm} \mathrm{Hg}$, INR $<1.4$ (quick $>60 \%$ ), and thrombocyte count $\geq 80 \mathrm{~g} / \mathrm{L}$ were used with few exceptions. Whenever justifiable, antiplatelet agents were discontinued 1 week before the procedure, but in some cases, biopsies were performed under aspirin or clopidogrel (however, never under dual antiplatelet therapy). Details of the biopsy procedure are given in the supplementary methods.

All patients had a control ultrasound four hours after biopsy, and their first urine voided after the procedure was inspected by a physician. Outpatients were discharged if they had no macrohematuria and no significant bleeding on ultrasound. All outpatients were seen in the outpatient nephrology clinic after the biopsy procedure to discuss the biopsy results and to be questioned for signs of complications.

\section{Study Outcomes}

As primary outcome, we chose the occurrence of major bleeding (any bleeding event requiring [i] surgical intervention, endovascular intervention [such as coiling or embolization], or catheter placement for gross hematuria; [ii] hospital admission after a planned outpatient procedure, transfer to the intensive care unit, prolongation of a planned hospital stay, or unplanned readmission; or [iii] blood transfusion). Secondary outcomes were the individual components of the primary outcome; bleeding resulting in a drop in hemoglobin of $>20 \mathrm{~g} / \mathrm{L}$; visible hematuria (including hematuria not requiring any intervention); bleeding complications graded according to the Common Terminology Criteria for Adverse Events (CTCAE) version 5.0 (https://ctep.cancer.gov/protocoldevelopment/electronic_applications/docs/CTCAE_v5_Quick_ Reference_5x7.pdf); any nonbleeding complications or unplanned CT imaging performed because of a suspected complication. 
Table 1. Baseline patient characteristics and procedural characteristics in all procedures

\begin{tabular}{|c|c|c|c|c|}
\hline $\begin{array}{l}\text { Procedures, } N \\
\text { Consent for data extraction from electronic health records }\end{array}$ & $\begin{array}{l}\text { All biopsies } \\
2,239 \\
2,020(90.2 \%)\end{array}$ & $\begin{array}{l}\text { Native kidneys } \\
733 \\
663(90.5 \%)\end{array}$ & $\begin{array}{l}\text { Transplant } \\
1,506 \\
1,357(90.1 \%)\end{array}$ & $\begin{array}{l}p \text { values for the } \\
\text { comparison of } \\
\text { native kidneys } \\
\text { versus transplant }\end{array}$ \\
\hline \multicolumn{5}{|l|}{ Patient characteristics } \\
\hline Age, yr & $50.6 \pm 15.0$ & $50.1 \pm 17.1$ & $50.8 \pm 13.8$ & 0.280 \\
\hline Female sex & $785(37.7 \%)$ & $304(45.0 \%)$ & $481(34.1 \%)$ & $<0.001$ \\
\hline Diabetes & $461(22.8 \%)$ & $87(13.1 \%)$ & $374(27.6 \%)$ & $<0.001$ \\
\hline Cirrhosis & $108(5.3 \%)$ & $43(6.5 \%)$ & $64(4.7 \%)$ & 0.093 \\
\hline Amyloidosis & $21(1.0 \%)$ & $15(2.2 \%)$ & $6(0.4 \%)$ & $<0.001$ \\
\hline \multicolumn{5}{|l|}{ Laboratory parameters } \\
\hline Creatinine, $\mu \mathrm{mol} / \mathrm{L}$ & $187(138-278)$ & $157(99-283)$ & $195(152-276)$ & 0.034 \\
\hline eGFR (CKD-EPI), $\mathrm{mL} / \mathrm{min} / 1.73 \mathrm{~m}^{2}$ & $37 \pm 25$ & $47 \pm 35$ & $33 \pm 18$ & $<0.001$ \\
\hline Outpatient procedures & $1,506(67.2 \%)$ & $430(58.6 \%)$ & $1,076(71.4 \%)$ & $<0.001$ \\
\hline Initial SBP, mm Hg & $139 \pm 21$ & $136 \pm 20$ & $141 \pm 21$ & 0.001 \\
\hline Initial DBP, mm Hg & $82 \pm 13$ & $81 \pm 13$ & $83 \pm 13$ & 0.042 \\
\hline Needle passes, $n$ & $2.4 \pm 1.0(1-9)$ & $2.7 \pm 1.1(1-9)$ & $2.3 \pm 1.0(1-9)$ & $<0.001$ \\
\hline Under aspirin & $39(1.7 \%)$ & $5(0.7 \%)$ & $34(2.3 \%)$ & 0.007 \\
\hline Under clopidogrel & $5(0.2 \%)$ & $0(0 \%)$ & $5(0.3 \%)$ & 0.118 \\
\hline DDAVP & $66(2.9)$ & $25(3.4)$ & $41(2.7)$ & 0.005 \\
\hline Previous biopsies performed by the same operator, $n$ & $23(11-44)$ & $25(13-45)$ & $22(9-44)$ & 0.420 \\
\hline
\end{tabular}

Shown are numbers and percentage, mean \pm SD, or median and interquartile range; for the number of needle passes, mean \pm SD and the range are given. Note that percentages relate to the total of patients with available information on the respective variable. SBP, systolic blood pressure; DBP, diastolic blood pressure; DDAVP, desmopressin.

\section{Statistical Analyses}

Descriptive statistics (calculation of means and standard deviation) were performed using Microsoft Excel. Multifactorial logistic regression was performed using SPSS version 25. Means were compared using student's $t$ test and proportions using a Z-test. Adjustment of $p$ values for multiple testing was performed using $\mathrm{R}$ ( $\mathrm{R}$ Core Team [2020]. R: a language and environment for statistical computing; R Foundation for Statistical Computing, Vienna, Austria. URL https://www.R-project.org/). For the assessment of the association between thrombocyte counts, hemoglobin, eGFR, INR, and SBP, each with the binary outcome major bleeding, splines with 9 degrees of freedom were fitted using $\mathrm{R}$.

\section{Results}

\section{Patient and Procedural Characteristics}

From January 2005 through December 2017, a total of 2239 kidney biopsies were performed in 1,468 patients. One thousand thirty-four patients received 1 biopsy, 239 patients 2,99 patients 3,66 patients 4,22 patients 5,3 pa- tients 6,2 patients 7 , and 3 patients a total of 8 biopsies during the study period. Seven hundred thirty-three (32.7\%) were native kidney biopsies and 1,506 (67.3\%) transplant biopsies. One thousand three hundred thirtythree patients (90.8\%) had given general consent for data use, corresponding to 2020 procedures (90.2\%). Patient and procedural characteristics for native versus transplant biopsies are given in Table 1.

\section{Complications of the Procedures}

The number and types of complications by native versus transplant kidney biopsies are listed in Table 2. Complications graded by CTCAE and major bleeding events by native versus transplant biopsies and by inpatient versus planned outpatient procedures are shown in Figure 1. Overall, 151 complications occurred, which corresponds to a rate of $6.7 \%$. Nearly all complications were bleeding events, the majority asymptomatic or minimally symptomatic (CTCAE grade 1), such as small hematomas de- 
Table 2. All complications by type of biopsy (native vs. transplant)

\begin{tabular}{llll}
$\begin{array}{l}\text { All biopsies } \\
(n=2,239)\end{array}$ & $\begin{array}{l}\text { Native kidneys } \\
(n=733)\end{array}$ & $\begin{array}{l}\text { Transplant } \\
(n=1,506)\end{array}$ & $\begin{array}{l}p \text { values (native } \\
\text { kidneys vs. } \\
\text { transplant })\end{array}$ \\
\hline
\end{tabular}

Any complication

CTCAE category 1

CTCAE category 2

CTCAE category 3

CTCAE category 4

CTCAE category 5

Major bleeding, $n(\%)$

Surgical intervention

Endovascular intervention

Catheter placement for gross hematuria

Hospital admission after a planned outpatient procedure

ICU admission, extension of hospital stay, or readmission

Blood transfusion

Nonmajor bleeding complications, $n(\%)$

Asymptomatic hematoma detected on routine ultrasound

Minor visible hematuria requiring no intervention

Signs/procedures related to possible bleeding, $n$ (\%)

CT for suspected complication

Hemoglobin drop by $>20 \mathrm{~g} / \mathrm{L}$ within 1 week after biopsy

Nonbleeding complications, $n(\%)$

AV-fistula

Vagal reaction

Local allergic reaction to lidocaine

$\begin{array}{rr}151(6.7) & 69(9.4) \\ 107(4.8) & 55(7.5) \\ 2(0.1) & 1(0.1) \\ 37(1.7) & 11(1.5) \\ 5(0.2) & 2(0.3) \\ 0 & 0 \\ 43(1.9) & 14(1.9) \\ 7(0.3) & 0(0) \\ 9(0.4) & 6(0.8) \\ 6(0.3) & 1(0.1) \\ 14(0.6) & 3(0.4) \\ 5(0.2) & 2(0.3) \\ 23(1.0) & 8(1.1) \\ & \\ 70(3.1) & 43(5.9) \\ 28(1.3) & 9(1.2) \\ & \\ 22(1.0) & 10(1.3) \\ 15(0.7) & 5(0.7) \\ & \\ 4(0.2) & 1(0.1) \\ 5(0.2) & 4(0.5) \\ 1(<0.1) & 1(0.1)\end{array}$

$82(5.4)$

$52(3.5)$

$1(0.1)$

$26(1.7)$

$3(0.2)$

0

$29(1.9)$

$7(0.5)$

$3(0.2)$

$5(0.3)$

$11(0.7)$

$3(0.2)$

$15(1.0)$

28 (1.9)

19 (1.3)

$12(0.8)$

$10(0.7)$

$3(0.2)$

$1(0.1)$

0 (0)
0.001

$<0.001$

0.644

0.687

0.743

$\mathrm{n} / \mathrm{a}$

0.980

0.005

0.002

0.003

0.366

0.729

0.834

$<0.001$

0.946

0.202

0.961

0.741

0.024

0.152

Shown are absolute numbers and percentage. AV, arteriovenous; CT, computed tomography; CTCAE, Common Terminology Criteria for Adverse Events, version 5 (grade 1 refers to mild symptoms, no intervention required, grade 2 to minimally invasive evacuation or aspiration indicated, grade 3 to transfusion, hospital admission, or invasive intervention indicated, grade 4 to lifethreatening consequences with urgent intervention indicated, and grade 5 to death); ICU, intensive care unit.

tected at routine postbiopsy ultrasound or mild macrohematuria not requiring intervention. The overall complication rate was higher in the native kidney compared to transplant biopsies, a difference that was entirely driven by a higher rate of asymptomatic hematomas detected on routine surveillance ultrasound. In total, 43 major bleeding events occurred (1.9\%) with no difference between native and transplant kidneys.

\section{Clinical Predictors of Complications}

Patient and procedural characteristics of all patients experiencing major bleeding compared to all patients with no complication (i.e., CTCAE 0) are shown in Table 3. Patients with major bleeding had a lower eGFR, a lower hemoglobin, were more often taking aspirin, more likely to have liver cirrhosis or amyloidosis, and tended to have higher preprocedure blood pressure. Likewise, in the univariate analysis, the risk to experience a major hemorrhage was higher in patients with amyloidosis
$(2 / 21=9.5 \%$ vs. $35 / 1,999=1.8 \% ; p=0.008)$, liver cirrhosis $(5 / 107=4.7 \%$ vs. $32 / 1,913=1.7 \% ; p=0.024)$, under aspirin (10.3 vs. $1.8 \% ; p<0.001)$, with hemoglobin $<105$ $\mathrm{g} / \mathrm{L}(19 / 702=2.7 \%$ vs. $5 / 1,062=0.5 \% ; p<0.001)$, with SBP $>160 \mathrm{~mm} \mathrm{Hg}(6 / 121=4.9 \%$ vs. $20 / 835=2.4 \% ; p=$ 0.049 ), and in patients with eGFR $<30 \mathrm{~mL} / \mathrm{min} / 1.73 \mathrm{~m}^{2}$ $(20 / 795=2.5 \%$ vs. $11 / 957=1.1 \% ; p=0.031)$ but did not differ significantly in males versus females $(2.1$ vs. $1.5 \%$; $p=0.311)$, diabetics $(8 / 46=1.7 \%$ vs. $29 / 1,559=1.9 \% ; p=$ $0.861)$, hypertension $(20 / 1,064=2.0 \%$ vs. $17 / 956=1.9 \%$; $p=0.894)$, patients with INR $>1.2(0 / 43=0 \%$ vs. $31 / 1,284$ $=2.4 \% ; p=0.303)$, or thrombocytes $<80 \mathrm{~g} / \mathrm{L}(1 / 25=4.0 \%$ vs. $21 / 1,594=1.3 \% ; p=0.250)$. Note that despite a safety margin of $80 \mathrm{~g} / \mathrm{L}$, a few biopsies were performed with lower thrombocyte counts ( $n=25$ in total; $n=8$ with thrombocytes $<60$ and $n=15$ with thrombocytes $60-79 \mathrm{~g} / \mathrm{L}$ ). In these procedures, 1 major bleeding event, defined by the need for transfusion, occurred in a patient with acute kidney injury and thrombocytes $58 \mathrm{~g} / \mathrm{L}$, but the need for 


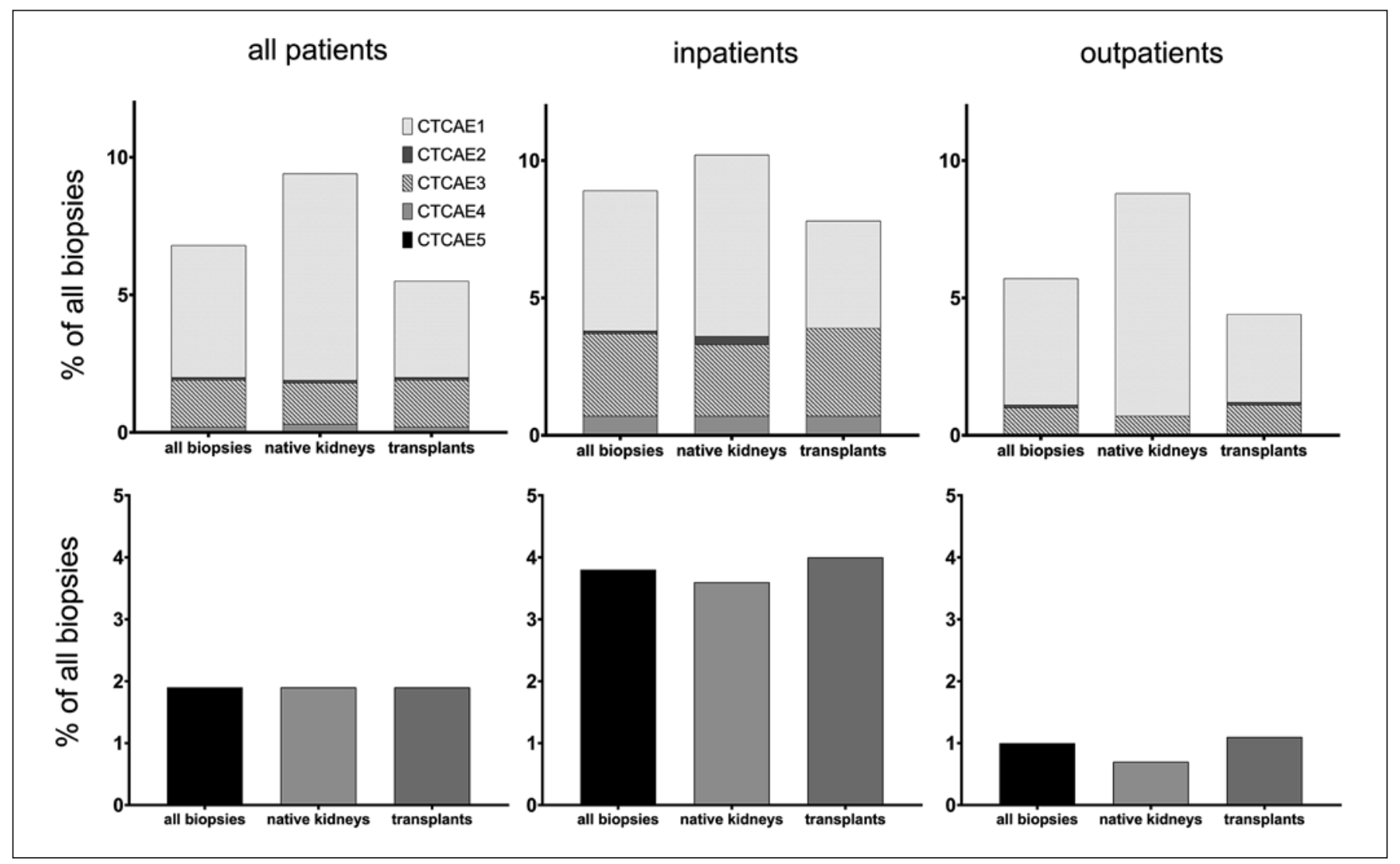

Fig. 1. Incidence of complications by CTCAE grade (upper panels) and of major bleeding (lower panels) by inpatient versus outpatient procedures and by native versus transplant kidney biopsy.

transfusion was likely not related to the biopsy procedure. The effect of preprocedure hemoglobin on major bleeding was only partially accounted for by the higher need for blood transfusion in these patients. When excluding blood transfusion from the definition of major bleeding, one of the other components of major bleeding occurred in $13 / 702=1.9 \%$ with hemoglobin $<105$ versus $3 / 1,062=$ $0.3 \%$ with hemoglobin $\geq 105 \mathrm{~g} / \mathrm{L}(p<0.001)$. The effect of systolic blood pressure, platelet count, hemoglobin, INR, and eGFR as continuous variables on major bleeding rate is shown in Figure 2.

We further performed a multifactorial logistic regression to identify independent predictors of bleeding (Table 4). Two models were used: one incorporating only clinical parameters that were available for most patients (model 1) and one incorporating laboratory parameters and blood pressure, which were available for only a subset of patients (model 2). Aspirin use and amyloidosis were significantly associated with major bleeding in model 1 but lost significance in model 2. In the latter model, he- moglobin and systolic blood pressure (first measurement at the day of the procedure) were significantly associated with major bleeding.

\section{Timing of the Complications}

The time to clinical manifestation or imaging-based diagnosis of major bleeding was assessed from clinical chart review for every case and ranged from immediately after the procedure to 14 days thereafter (median $4 \mathrm{~h}$ ). Of note, bleeding complications tended to manifest later in inpatients compared to planned outpatients (median 5.5 vs. $4.0 \mathrm{~h}$ with 51.9 vs. $21.4 \%$ of all major bleeding episodes manifesting $>4 \mathrm{~h}$ and $14.8 \%$ vs. $7.1 \%>24 \mathrm{~h}$ after the procedure; Fig. 3).

\section{Complication Rate in Kidney Biopsies Planned as \\ Outpatient Procedures}

One thousand five hundred seven kidney biopsies (67.3\%, $58.6 \%$ of all native and $71.5 \%$ of all transplant kidney biopsies) were scheduled as outpatient proce- 
Table 3. Comparison of baseline and procedural characteristics between patients with major bleeding and those without bleeding complications

\begin{tabular}{|c|c|c|c|}
\hline & $\begin{array}{l}\text { Major bleeding } \\
(N=43)\end{array}$ & $\begin{array}{l}\text { No complication } \\
(N=2,088)\end{array}$ & $p$ value \\
\hline \multicolumn{4}{|l|}{ Patient characteristics } \\
\hline Age, yr & $51.2 \pm 15.7$ & $50.6 \pm 15.0$ & 0.807 \\
\hline Female sex, $n(\%)$ & $13(30.2)$ & $780(37.4)$ & 0.337 \\
\hline Hypertension, $n(\%)$ & $20(52.6)$ & $994(52.7)$ & 0.870 \\
\hline Diabetes, $n(\%)$ & $8(21.6)$ & $435(23.0)$ & 0.837 \\
\hline Cirrhosis, $n(\%)$ & $5(13.5)$ & $102(5.4)$ & 0.033 \\
\hline Amyloidosis, $n(\%)$ & $2(5.4)$ & $18(1.0)$ & 0.008 \\
\hline \multicolumn{4}{|l|}{ Laboratory parameters } \\
\hline eGFR (CKD-EPI), mL/min/1.73 m² & $27.5 \pm 27.8$ & $37.3 \pm 24.9$ & 0.030 \\
\hline Hemoglobin, g/L & $92 \pm 19$ & $111 \pm 22$ & $<0.001$ \\
\hline Thrombocytes, g/L & $217 \pm 89$ & $248 \pm 98$ & 0.143 \\
\hline INR & $1.05 \pm 0.10$ & $1.03 \pm 0.10$ & 0.422 \\
\hline \multicolumn{4}{|l|}{ Procedural characteristics } \\
\hline Initial SBP, mm Hg & $145 \pm 20$ & $139 \pm 21$ & 0.145 \\
\hline Initial DBP, mm Hg & $86 \pm 12$ & $82 \pm 13$ & 0.100 \\
\hline Needle passes, $n$ & $2.6 \pm 1.2$ & $2.4 \pm 1.0$ & 0.437 \\
\hline Under aspirin, $n(\%)$ & $4(9.3)$ & $33(1.6)$ & $<0.001$ \\
\hline Previous biopsies performed by the same operator, $n$ & $35.1 \pm 33.6$ & $34.4 \pm 34.3$ & 0.900 \\
\hline$<5$ previous biopsies performed by the same operator, $n(\%)$ & $3(7.0)$ & $207(9.9)$ & 0.522 \\
\hline \multicolumn{4}{|c|}{$\begin{array}{l}\text { Shown are numbers and percentage or mean and SD. Note that percentages relate to the total of patients with } \\
\text { available information on the respective variable. The differences in amyloidosis, aspirin use, and hemoglobin } \\
\text { remained significant after adjustment for multiple testing using false discovery rate. SBP, systolic blood pressure; } \\
\text { DBP, diastolic blood pressure. }\end{array}$} \\
\hline
\end{tabular}

Table 4. Prediction of major bleeding by multifactorial logistic regression

\begin{tabular}{|c|c|c|c|c|}
\hline & \multicolumn{2}{|c|}{ Model $1(N=1,973)$} & \multicolumn{2}{|c|}{ Model $2(N=713)$} \\
\hline & B & $p$ & B & $p$ \\
\hline Age & -0.006 & 0.598 & -0.022 & 0.338 \\
\hline Male sex & 0.205 & 0.575 & 0.232 & 0.740 \\
\hline Aspirin & 1.777 & 0.008 & 2.324 & 0.085 \\
\hline Passes, $n$ & -0.003 & 0.588 & 0.266 & 0.321 \\
\hline Physician experience & 0.125 & 0.371 & -0.032 & 0.057 \\
\hline Hypertension & -0.013 & 0.971 & -0.387 & 0.540 \\
\hline Diabetes & -0.176 & 0.676 & -0.693 & 0.415 \\
\hline Amyloidosis & 1.787 & 0.026 & 1.643 & 0.209 \\
\hline Liver cirrhosis & 0.942 & 0.062 & 1.434 & 0.142 \\
\hline eGFR CKD-EPI & & & -0.006 & 0.762 \\
\hline Hemoglobin & & & -0.049 & 0.012 \\
\hline INR & & & -2.201 & 0.547 \\
\hline Thrombocytes & & & 0.001 & 0.722 \\
\hline SBP & & & 0.043 & 0.007 \\
\hline
\end{tabular}

Factors with a $p$ value of $<0.05$ in the respective analysis are shown in bold. $\mathrm{B}$, unstandardized beta; $p, p$ value. 


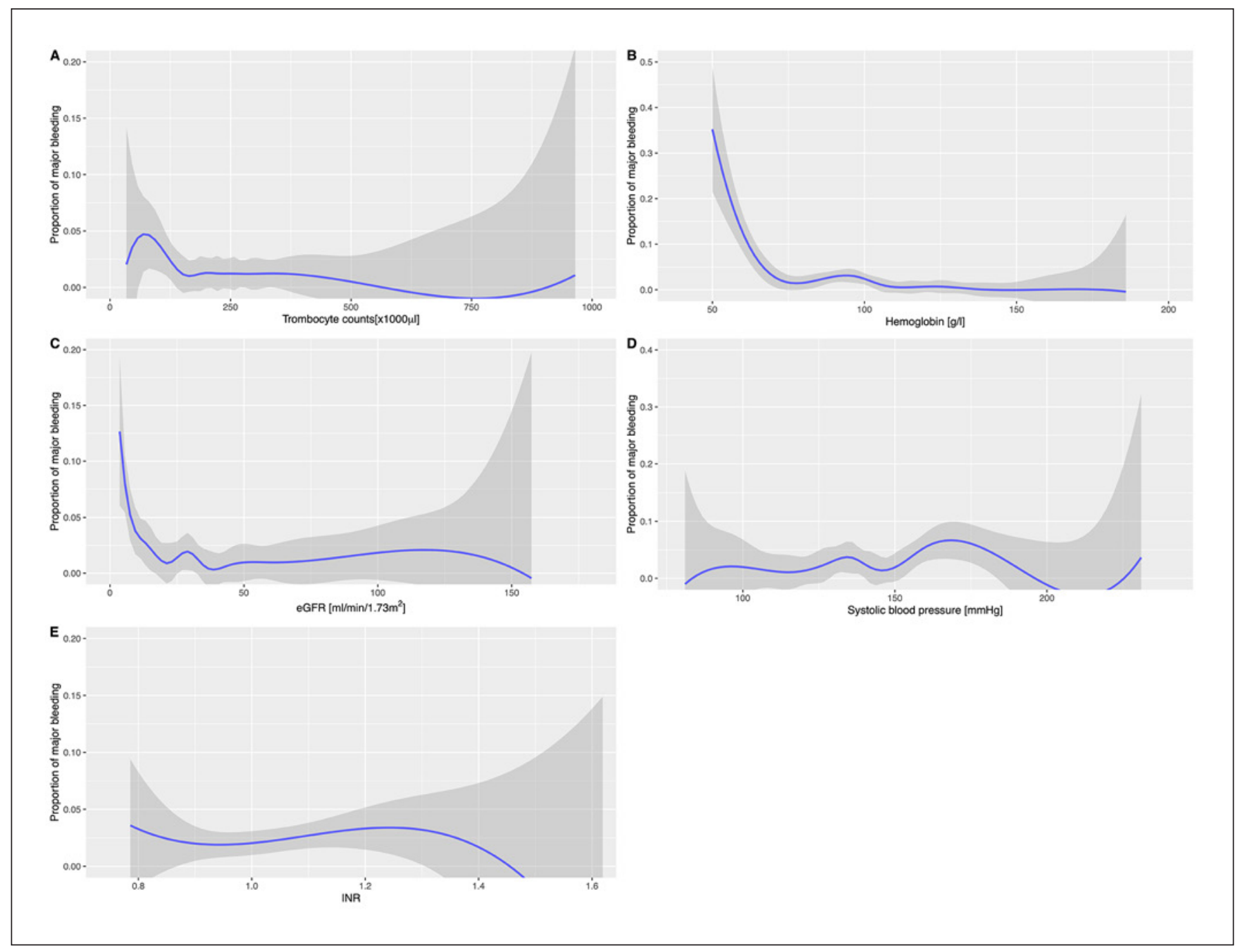

Fig. 2. Rate of major bleeding by preprocedure thrombocyte counts (A), hemoglobin (B), eGFR (C), systolic blood pressure (first measurement of the day, D), and INR (E) fitted by splines with 9 degrees of freedom. The $95 \%$ confidence interval is shown by gray shading.

dures. Characteristics of these patients compared to inpatients are shown in Table 5, and complication rates for inpatients versus outpatients and transplant versus native kidney biopsies are listed in Table 6. Major bleeding occurred significantly more often after inpatient versus planned outpatient procedures (28/732, 3.8\% vs. $15 / 1,507$, $1.0 \%$; $p<0.001)$. Of note, 8 of the 15 major bleeding episodes ( 2 native and 6 transplant kidneys) occurring after planned outpatient biopsies did not require intervention and qualified as major bleeding only due to hospital admission for overnight surveillance. Of the remaining 7 major bleeding events, 3 required catheter placement for gross hematuria, 3 a transfusion, and 1 operative revision of a transplant kidney. Most major bleeding episodes in planned outpatients were detected during the 4-h postbiopsy surveillance period with only 3 manifesting after outpatients had left the hospital (all of them were transplant kidneys). One patient experienced gross hematuria with consecutive tamponade and readmission for urinary retention after $24 \mathrm{~h}$. Another patient developed flank pain 6 days after the procedure due to retroperitoneal hematoma and required a blood transfusion but no other intervention. The third patient felt pain in the iliac fossa shortly after leaving the hospital and was readmitted for operative revision of the transplant kidney. 
Fig. 3. Manifestation of major bleeding by time after the procedure. Shown is the number (upper panel) or the percentage (lower panel) of major bleeding episodes in specified time intervals after the procedure, separated by planned outpatient versus inpatient procedures. h, hours; w, weeks.
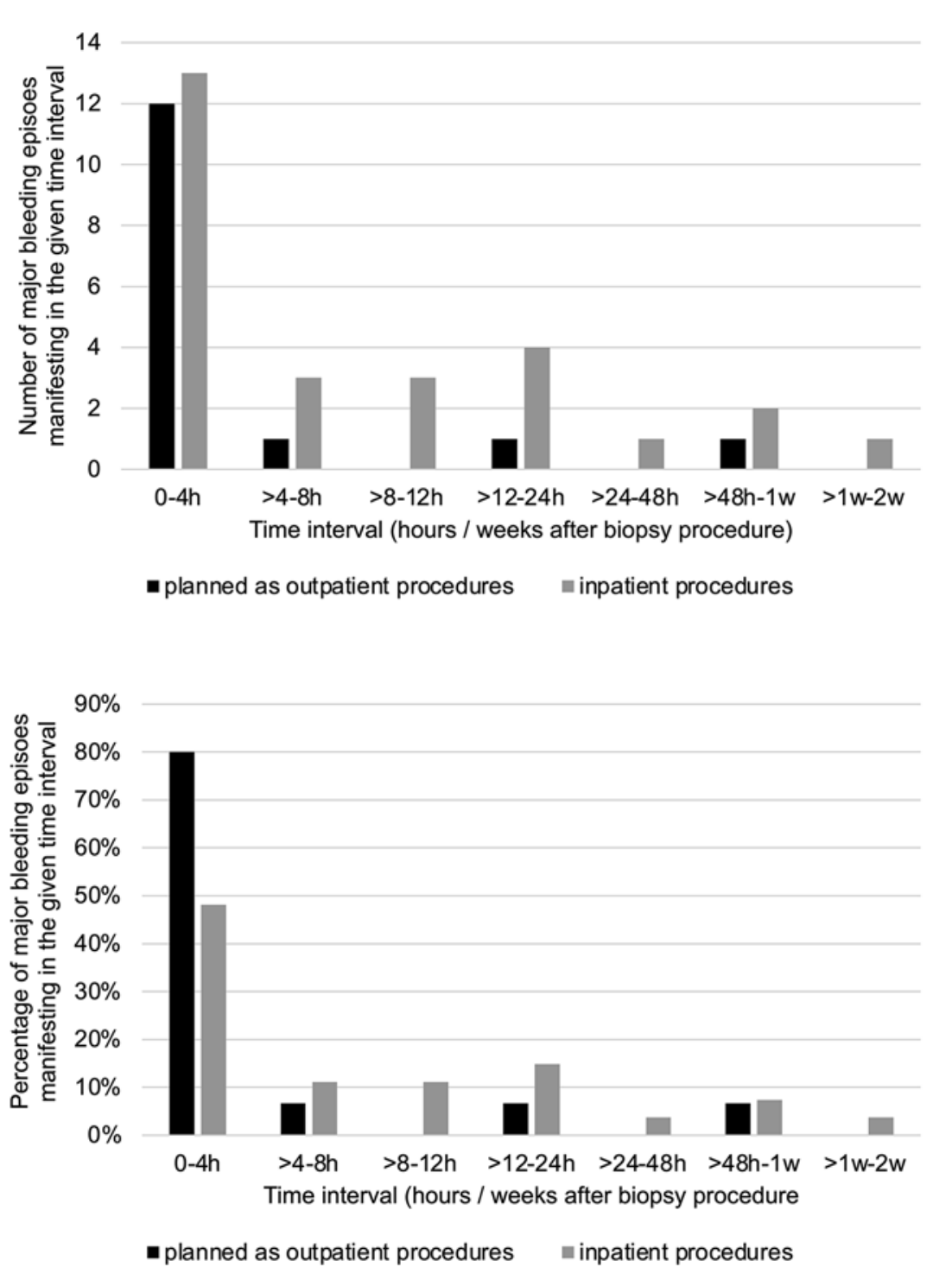

\section{Predictive Value of 4-h Postbiopsy Ultrasound} Examination in Outpatient Biopsies

All patients with major bleeding episodes detected before discharge from a planned outpatient kidney biopsy were symptomatic (macrohematuria, pain, urinary retention, or hypotension) before the scheduled postbiopsy ultrasound. In the 3 outpatients with major bleeding detected after hospital discharge, no hematoma was noted during the 4 -h postbiopsy ultrasound. None of the 40 asymptomatic patients with minor hematoma detected during routine postbiopsy ultrasound developed symptomatic bleeding later on.

Complications of Outpatient Kidney Biopsy

\section{Operator Experience and Complication Rate}

Most kidney biopsies were performed by nephrology fellows as operators under supervision of an experienced staff physician who held the ultrasound probe ("sonographer"). During the observation period, 57 physicians performed kidney biopsies as operators. The average number of biopsies performed per operator was 39 (range 1-176), and the operators had a median experience of 23 prior biopsies. Operator experience did not differ significantly between procedures with major bleeding versus without complication, and the rate of major bleeding events was not different between biopsies performed by 
Table 5. Patient characteristics of outpatient versus inpatient biopsies

\begin{tabular}{|c|c|c|c|}
\hline & $\begin{array}{l}\text { Outpatient procedures } \\
(N=1,507)\end{array}$ & $\begin{array}{l}\text { Inpatient procedures } \\
(N=732)\end{array}$ & $p$ value \\
\hline \multicolumn{4}{|l|}{ Patient characteristics } \\
\hline Age, yr & $49.2 \pm 14.5$ & $53.5 \pm 15.7$ & $<0.001$ \\
\hline Female sex, $n(\%)$ & $557(37.0)$ & $286(39.1)$ & 0.334 \\
\hline Hypertension, $n(\%)$ & $727(53.4)$ & $337(51.2)$ & 0.362 \\
\hline Diabetes, $n(\%)$ & $305(22.4)$ & $156(23.7)$ & 0.510 \\
\hline Cirrhosis, $n(\%)$ & $59(4.3)$ & $48(7.3)$ & 0.005 \\
\hline Amyloidosis, $n(\%)$ & $10(0.7)$ & $11(1.7)$ & 0.051 \\
\hline \multicolumn{4}{|l|}{ Laboratory parameters } \\
\hline eGFR (CKD-EPI), mL/min/1.73 m² & $43.0 \pm 24.3$ & $25.6 \pm 22.8$ & $<0.001$ \\
\hline Hemoglobin, g/L & $119 \pm 19$ & $94 \pm 19$ & $<0.001$ \\
\hline Thrombocytes, g/L & $249 \pm 90$ & $241 \pm 113$ & 0.116 \\
\hline INR & $1.02 \pm 0.10$ & $1.06 \pm 0.10$ & $<0.001$ \\
\hline \multicolumn{4}{|l|}{ Procedural characteristics } \\
\hline Initial SBP, mm Hg & $139 \pm 21$ & $139 \pm 21$ & 0.612 \\
\hline Initial DBP, mm Hg & $84 \pm 12$ & $80 \pm 14$ & $<0.001$ \\
\hline Under aspirin, $n(\%)$ & $10(0.7)$ & $29(4.0)$ & $<0.001$ \\
\hline
\end{tabular}

Shown are numbers and percentage or mean and SD. Note that percentages relate to the total of patients with available information on the respective variable. SBP, systolic blood pressure; DBP, diastolic blood pressure.

Table 6. All complications by inpatient versus outpatient and native versus transplant biopsies

\begin{tabular}{|c|c|c|c|c|}
\hline & \multicolumn{2}{|c|}{ Inpatient procedures } & \multicolumn{2}{|c|}{ Outpatient procedures } \\
\hline Any complication, $n(\%)$ & $31(10.2)$ & $34(7.9)$ & $38(8.8)$ & $48(4.5)$ \\
\hline CTCAE category 1 & $20(6.6)$ & $17(3.9)$ & $35(8.1)$ & $35(3.2)$ \\
\hline CTCAE category 2 & $1(0.3)$ & 0 & 0 & $1(0.1)$ \\
\hline CTCAE category 3 & $8(2.6)$ & $14(3.2)$ & $3(0.7)$ & $12(1.1)$ \\
\hline Major bleeding, $n(\%)$ & $11(3.6)$ & $17(4.0)$ & $3(0.7)$ & $12(1.1)$ \\
\hline Surgical intervention & 0 & $6(1.4)$ & 0 & $1(0.1)$ \\
\hline Endovascular intervention & $6(2.0)$ & $3(0.7)$ & 0 & 0 \\
\hline Catheter placement for gross hematuria & $1(0.3)$ & $2(0.4)$ & 0 & $3(0.3)$ \\
\hline Hospital admission after a planned outpatient procedure & $\mathrm{n} / \mathrm{a}$ & $\mathrm{n} / \mathrm{a}$ & $3(0.7)$ & $10(0.9)$ \\
\hline ICU admission, extension of hospital stay or readmission & $2(0.7)$ & $1(0.2)$ & 0 & $2(0.6)$ \\
\hline \multicolumn{5}{|l|}{ Nonmajor bleeding complications, $n(\%)$} \\
\hline \multicolumn{5}{|l|}{ Signs/procedures related to possible bleeding, $n$ (\%) } \\
\hline CT for suspected complication & $9(3.0)$ & $5(1.2)$ & $1(0.2)$ & $7(0.6)$ \\
\hline Hemoglobin drop by $>20 \mathrm{~g} / \mathrm{L}$ within 1 week after biopsy & $4(1.3)$ & $8(1.9)$ & $1(0.2)$ & $2(0.2)$ \\
\hline \multicolumn{5}{|l|}{ Nonbleeding complications, $n(\%)$} \\
\hline AV-fistula & $1(0.3)$ & 0 & 0 & $3(0.3)$ \\
\hline Vagal reaction & $1(0.3)$ & 0 & $3(0.7)$ & $1(0.1)$ \\
\hline Local allergic reaction to lidocaine & $1(0.2)$ & 0 & 0 & 0 \\
\hline
\end{tabular}

Shown are absolute numbers and percentage. AV, arteriovenous; CT, computed tomography; CTCAE, Common Terminology Criteria for Adverse Events, version 5 (grade 1 refers to mild symptoms, no intervention required, grade 2 to minimally invasive evacuation or aspiration indicated, grade 3 to transfusion, hospital admission, or invasive intervention indicated, grade 4 to lifethreatening consequences with urgent intervention indicated, and grade 5 to death); ICU, intensive care unit. 
operators who had performed $<5$ prior procedures versus more experienced operators (Table 3). Operator experience was also not significantly associated with the complication rate in the multifactorial analysis (Table 4).

\section{Discussion}

Kidney biopsy remains a cornerstone in the diagnosis of many renal diseases and in establishing the cause of transplant kidney dysfunction. Technical advances, such as real-time ultrasound guidance, have reduced the complication rate over the last decades. Several reports on the incidence of complications of renal biopsies have been published, yet large studies ( $>1,000$ patients) remain scarce. Our study represents one of the largest series of kidney biopsies and the largest detailed analysis in a cohort consisting of similar numbers of transplant and native kidney biopsies. In particular, this is the first report on the feasibility of both transplant and native kidney biopsies performed as an outpatient procedure in a large cohort.

Our study confirms the safe nature of kidney biopsies, both native and transplant. We observed a complication rate of $6.7 \%$ and a rate of major bleeding of $1.9 \%$. The rate of complications requiring intervention was even lower at $1.0 \%$. The rate of major bleeding was similar between native and transplant kidney biopsies. Overall complication rate was somewhat higher in native kidneys due to an increased rate of asymptomatic hematoma detected by routine postbiopsy ultrasound, probably explained by the superficial position of transplant kidneys allowing for better mechanical hemostasis immediately after biopsy. Our complication numbers were generally in agreement with previous reports [8-12] with some differences explained by a number of factors. First, patient populations were not uniform. Second, there is no universally accepted definition of major bleeding after interventional procedures. Some studies reported adverse events graded by the CTCAE, but studies even differ in the application of this classification. According to the CTCAE version 5.0, we classified complications leading to hospital admission or transfusion as CTCAE grade 3, which were both classified as CTCAE grade 2 in a previous study [10]. Several complications after planned outpatient procedures qualified as major bleeding due to hospital admission for overnight surveillance, which would have been considered mild complications in inpatient procedures. In order to facilitate the comparability of data, we report all components of the primary endpoint and several secondary

Complications of Outpatient Kidney

Biopsy endpoints. A third source of between-study variation is caused by detection bias. A majority of CTCAE grade 1 events in our study represented asymptomatic hematomas, which would have gone undetected if no postbiopsy ultrasound was performed [10].

In our unadjusted analysis, we identified continued aspirin use, reduced renal function, anemia, $\mathrm{SBP}>160 \mathrm{~mm}$ $\mathrm{Hg}$, amyloidosis, and liver cirrhosis as risk factors for major bleeding. In the multifactorial analysis including all relevant laboratory parameters, many of these factors lost significance. This was partially due to a loss of statistical power, since laboratory variables and blood pressure measurements were available only in a subset of patients. On the other hand, some of the variables were highly intercorrelated. Continued aspirin use was more common in patients with lower eGFR, possibly because obtaining a histological diagnosis was considered more urgent in these patients. Thus, the increased bleeding risk of a low eGFR might not be explained only by uremic thrombocytopathy but partially also by a higher percentage of aspirin use in these patients. Low hemoglobin has been previously associated with an increased risk of major bleeding [13-19], possibly because transfusion and intervention thresholds are reached even after moderate bleeding in patients with low baseline hemoglobin. However, even when excluding blood transfusion as a component from major bleeding, we still found more relevant bleeding episodes in patients with low hemoglobin levels. Hemoglobin levels were correlated with eGFR, such that one factor might confound the other. Taken together, it is difficult to assess causality of the individual risk factors since some of them are highly intercorrelated. From the curve fitting models shown in Figure 2, bleeding risk appears to increase particularly with hemoglobin $<70 \mathrm{~g} / \mathrm{L}$ and eGFR $<30 \mathrm{~mL} / \mathrm{min} / 1.73 \mathrm{~m}^{2}$. The effect of blood pressure appeared to be small (Fig. 2). However, we were not able to retrieve the blood pressure values immediately before the procedure from the system and thus used the first measurement on the day of the procedure for analysis. Furthermore, biopsies were not performed if blood pressure could not be lowered to $<160 / 110 \mathrm{~mm} \mathrm{Hg}$ before the procedure. Thus, our study cannot answer the question if higher preprocedure blood pressure values are associated with bleeding, but the safety threshold of $160 / 110 \mathrm{~mm} \mathrm{Hg}$ before the procedure used at our institution appears to be safe. Major bleeding was not associated with thrombocyte count or INR. However, only very few biopsies were performed with INR $>1.2$ or thrombocyte count $<80 \mathrm{~g} / \mathrm{L}$. This is also reflected by the wide $95 \%$ confidence interval of major bleeding risk with low platelet counts/high INR 


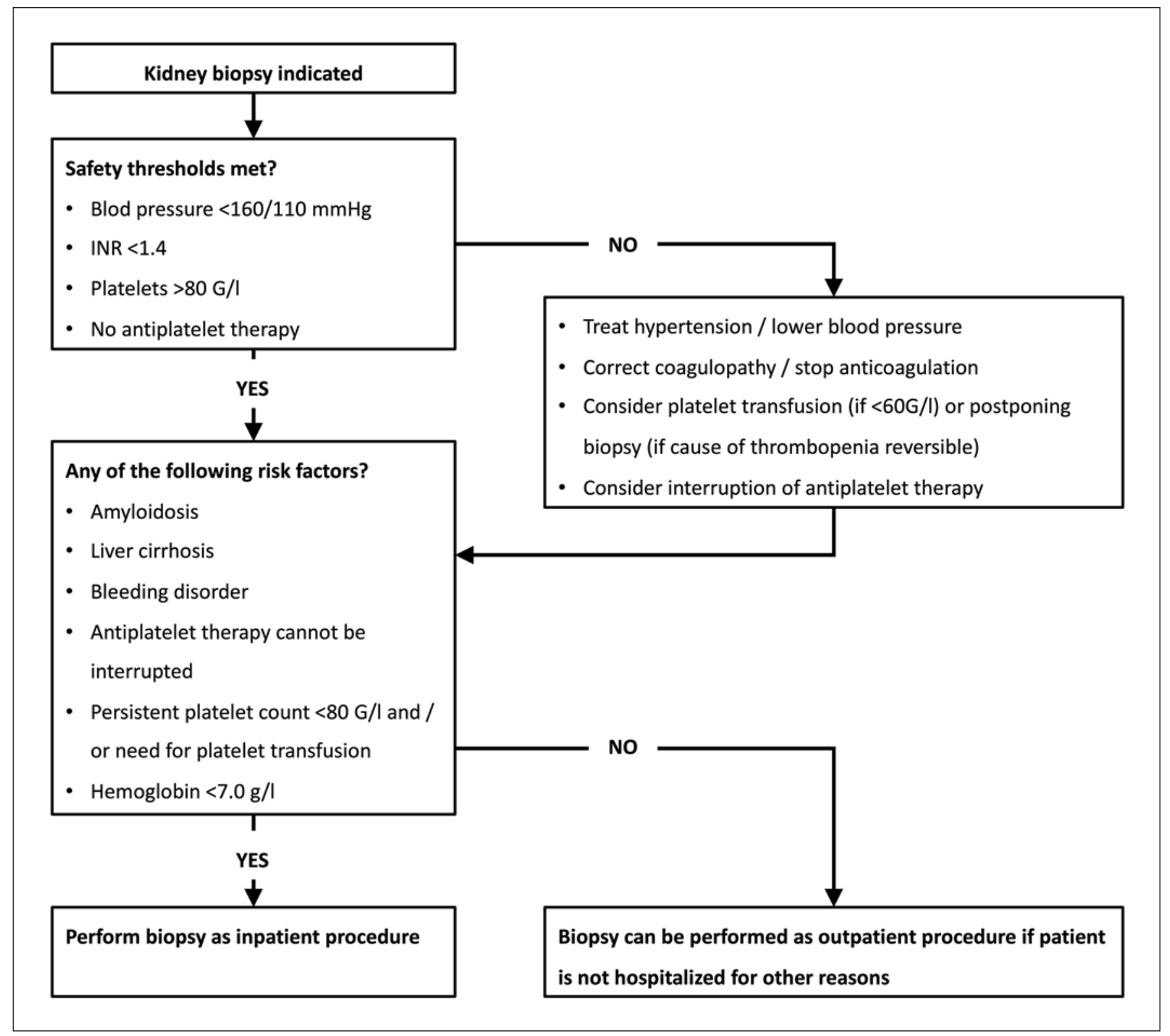

Fig. 4. Suggested flowchart to identify patients with higher risk of bleeding that warrant overnight postbiopsy surveillance as inpatients.

in Figure 2. Overall, our safety margins for kidney biopsies (thrombocyte count $>80 \mathrm{~g} / \mathrm{L}$ and INR $<1.4$ ) appear to be safe, and a lower threshold (e.g., thrombocyte count $>60 \mathrm{~g} / \mathrm{L}$ ) might also be reasonable.

We found a higher incidence of major bleeding in inpatients versus outpatients. We routinely perform all kidney biopsies as outpatient procedures unless there are other indications for hospital admission; hence, outpatients were not highly selected. However, inpatients clear- ly constituted a different patient population, including transplant patients in the early posttransplantation phase, acute kidney injury, and patients with other unstable conditions. These patients are more prone to disturbances of the coagulation system, receive more medications that might interfere with blood coagulation, and had more of the above-discussed risk factors for bleeding (Table 5). Furthermore, inpatients might be subject to detection bias as they are more closely monitored, usually including 
repetitive measurement of hemoglobin values and imaging for other purposes.

A major finding of our study is that kidney biopsies can be performed safely as an outpatient procedure with a postprocedure observation period as short as $4 \mathrm{~h}$. A few previous studies have reported transplant biopsies as an outpatient procedure $[9,10]$, whereas another [12] has advocated an observation period of $24 \mathrm{~h}$ after native kidney biopsy. To the best of our knowledge, only a few small studies have reported the experience of outpatient native kidney biopsies [20-27] with postprocedure observation periods ranging from 4 to $8 \mathrm{~h}$. Previous studies found that a relevant number of complications occurred $>4 \mathrm{~h}$ after the procedure $[20,28]$. In contrast, the majority of complications in our cohort manifested within $4 \mathrm{~h}$ after the procedure and only 3 after hospital discharge. Could we have missed complications due to early discharge? This is very unlikely, since all patients were followed up in the outpatient clinic and none was lost to follow-up. While minor and asymptomatic complications might have been missed in outpatients, all relevant complications have been detected. Of the complications occurring after hospital discharge, one manifested within $8 \mathrm{~h}$, a second by 24 $\mathrm{h}$, and the third even considerably later. Thus, there exists no meaningful cutoff after which no complications occur, which is in line with previous reports $[20,28]$, but a 4 -h observation period will detect the majority of complications. None of the late complications was life threatening or critical, and patients could be readmitted in stable conditions. Overall, we performed 430 native and 1,077 transplant kidney biopsies as outpatient procedures without a single fatal, life- or organ-threatening complication. Key for implementation of such a strategy is that the patients do not live in remote areas and have relatively easy access to hospital readmission.

One-hour postprocedure ultrasound has previously been reported to be unspecific but sensitive for bleeding complications after renal biopsy [29]. In contrast, our data do not support the practice of routine postprocedure ultrasound, since it was neither sensitive for late complications nor specific. However, it appears reasonable that the clinician assesses the overall status of the patient and checks the urine for gross hematuria before the discharge of outpatients.

Our study has certain limitations. First, not all potential complications have been systematically assessed (e.g., pain), and complications were entered as free text in our internal quality control database. To ensure that no relevant complication was missed, we manually reviewed all cases with potential hints to a complication in the EHR search and all cases with a complication listed in the internal database. Second, some parameters that were retrieved from the EHR were available only for a subset of patients (i.e., after the introduction and continued refinement of the EHR system). Finally, some asymptomatic complications, such as AV-fistulas, may have gone undetected.

\section{Conclusion}

Kidney biopsies are an overall safe procedure with major complications being similar between native and transplant kidney biopsies. Kidney biopsies can be safely performed as an outpatient procedure with an observation period as short as $4 \mathrm{~h}$, and routine postbiopsy ultrasound may not be necessary. Complications are more frequent in acutely ill patients and in patients with certain clinical characteristics such as aspirin use, low eGFR, anemia, liver cirrhosis, and amyloidosis. Based on our experience (safety of outpatient kidney biopsy procedures with the thresholds for blood pressure, thrombocyte count, and INR that we have used) as well as the risk factors for complications that we have observed in our study, we propose a flowchart to aid the decision whether an outpatient biopsy is feasible and to identify patients with increased risk of bleeding (Fig. 4).

\section{Statement of Ethics}

The study was approved by the Cantonal Ethics Committee of Zurich (BASEC-Nr. 2016-01166). Patients were exempt from giving written informed consent for this study because of unjustified efforts and since a large proportion of patients could not be contacted for consenting due to loss to follow-up, which would have caused potential bias. However, the majority of the patients have given general consent to data use for research, and data extraction from the EHR was limited to these patients.

\section{Conflict of Interest Statement}

The authors declare that they have no conflicts of interest.

\section{Funding Sources}

The authors have received no funding for this study. 


\section{Author Contributions}

Study conception/design: M.B., A.D.K., and H.S.; data acquisition: M.B., A.D.K., H.S., and N.W.; statistical analysis: A.D.K.; data analysis/interpretation: M.B., A.D.K., J.L., H.S., and R.P.W.; super- vision or mentorship: R.P.W. Each author contributed important intellectual content during manuscript drafting and accepts accountability for the overall work by ensuring that questions pertaining to the accuracy or integrity of any portion of the work are appropriately investigated and resolved.

\section{References}

1 Coresh J. Update on the burden of CKD. J Am Soc Nephrol. 2017;28(4):1020-2.

2 Saran R, Robinson B, Abbott KC, Agodoa LYC, Bragg-Gresham J, Balkrishnan R, et al. US renal data system 2018 annual data report: epidemiology of kidney disease in the United States. Am J Kidney Dis. 2019;73(3):A7-A8.

3 An Y, Zhang H, Liu Z. Individualizing therapy in lupus nephritis. Kidney Int Rep. 2019; 4(10):1366-72.

4 Ricklin D, Mastellos DC, Reis ES, Lambris JD. The renaissance of complement therapeutics. Nat Rev Nephrol. 2018;14(1):26-47.

5 Neuen BL, Young T, Heerspink HJL, Neal B, Perkovic V, Billot L, et al. SGLT2 inhibitors for the prevention of kidney failure in patients with type 2 diabetes: a systematic review and meta-analysis. Lancet Diabetes Endocrinol. 2019;7(11):845-54.

6 McClure M, Gopaluni S, Jayne D, Jones R. B cell therapy in ANCA-associated vasculitis: current and emerging treatment options. Nat Rev Rheumatol. 2018;14(10):580-91.

7 Schrezenmeier E, Jayne D, Dorner T. Targeting B cells and plasma cells in glomerular diseases: translational perspectives. J Am Soc Nephrol. 2018;29(3):741-58.

8 Abuelo JG. How long should patients be observed after percutaneous kidney biopsies? Nephrol Dial Transplant. 2019;34(11):197981

9 Schwarz A, Gwinner W, Hiss M, Radermacher J, Mengel M, Haller H. Safety and adequacy of renal transplant protocol biopsies. Am J Transplant. 2005;5(8):1992-6.

10 Redfield RR, McCune KR, Rao A, Sadowski E, Hanson M, Kolterman AJ, et al. Nature, timing, and severity of complications from ultrasound-guided percutaneous renal transplant biopsy. Transpl Int. 2016;29(2):167-72.

11 Tondel C, Vikse BE, Bostad L, Svarstad E. Safety and complications of percutaneous kidney biopsies in 715 children and 8573 adults in Norway 1988-2010. Clin J Am Soc Nephrol. 2012;7(10):1591-7.
12 Prasad N, Kumar S, Manjunath R, Bhadauria D, Kaul A, Sharma RK, et al. Real-time ultrasound-guided percutaneous renal biopsy with needle guide by nephrologists decreases postbiopsy complications. Clin Kidney J. 2015; $8(2): 151-6$

13 Hellem AJ, Borchgrevink CF, Ames SB. The role of red cells in haemostasis: the relation between haematocrit, bleeding time and platelet adhesiveness. Br J Haematol. 1961;7: 42-50.

14 Livio M, Marchesi D, Remuzzi G, Gotti E Mecca G, de Gaetano G. Uraemic bleeding: role of anaemia and beneficial effect of red cell transfusions. Lancet. 1982;2(8306):1013-5.

15 Moia M, Vizzotto L, Cattaneo M, Mannuccio Mannucci P, Casati S, Ponticelli C, et al. Improvement in the haemostatic defect of uraemia after treatment with recombinant human erythropoietin. Lancet. 1987;2(8570):1227-9.

16 Viganò $G$, Benigni $A$, Mendogni $D$, Mingardi G, Mecca G, Remuzzi G. Recombinant human erythropoietin to correct uremic bleeding. Am J Kidney Dis. 1991;18(1):44-9.

17 Beyth RJ, Quinn LM, Landefeld CS. Prospective evaluation of an index for predicting the risk of major bleeding in outpatients treated with warfarin. Am J Med. 1998;105(2):91-9.

18 Giustino G, Kirtane AJ, Baber U, Généreux P, Witzenbichler B, Neumann FJ, et al. Impact of anemia on platelet reactivity and ischemic and bleeding risk: from the assessment of dual antiplatelet therapy with drug-eluting stents study. Am J Cardiol. 2016;117(12):1877-83.

19 Vicente-Ibarra N, Marin F, Pernias-Escrig V, Sandin-Rollan M, Nunez-Martinez L, Lozano $\mathrm{T}$, et al. Impact of anemia as risk factor for major bleeding and mortality in patients with acute coronary syndrome. Eur J Intern Med. 2019;61:48-53.
20 Simard-Meilleur MC, Troyanov S, Roy L, Dalaire E, Brachemi S. Risk factors and timing of native kidney biopsy complications. Nephron Extra. 2014;4(1):42-9.

21 Fraser IR, Fairley KF. Renal biopsy as an outpatient procedure. Am J Kidney Dis. 1995; 25(6):876-8

22 Lin WC, Yang Y, Wen YK, Chang CC. Outpatient versus inpatient renal biopsy: a retrospective study. Clin Nephrol. 2006;66(1):1724.

23 Maya ID, Maddela P, Barker J, Allon M. Percutaneous renal biopsy: comparison of blind and real-time ultrasound-guided technique. Semin Dial. 2007;20(4):355-8.

24 Margaryan A, Perazella MA, Mahnensmith RL, Abu-Alfa AK. Experience with outpatient computed tomographic-guided renal biopsy. Clin Nephrol. 2010;74(6):440-5.

25 Jiang SH, Karpe KM, Talaulikar GS. Safety and predictors of complications of renal biopsy in the outpatient setting. Clin Nephrol. 2011;76(6):464-9.

26 Carrington CP, Williams A, Griffiths DF, Riley SG, Donovan KL. Adult day-case renal biopsy: a single-centre experience. Nephrol Dial Transplant. 2011;26(5):1559-63.

27 McMahon GM, McGovern ME, Bijol V, Benson CB, Foley R, Munkley K, et al. Development of an outpatient native kidney biopsy service in low-risk patients: a multidisciplinary approach. Am J Nephrol. 2012;35(4): 321-6.

28 Korbet SM, Whittier WL, Rodby RA. Changing trends in the performance of percutaneous renal biopsy from nephrologist to interventional radiologist: a single-center experience. Am J Nephrol. 2018;48(5):326-9.

29 Waldo B, Korbet SM, Freimanis MG, Lewis EJ. The value of post-biopsy ultrasound in predicting complications after percutaneous renal biopsy of native kidneys. Nephrol Dial Transplant. 2009;24(8):2433-9. 